\title{
Psychological and Philosophical Readings of the Spectatorship of Bollywood and Indian Tamil Film in Sri Lanka
}

\author{
Manoj Jinadasa \\ University of Kelaniya, Kelaniya, Sri Lanka
}

\begin{abstract}
The objective of this study is to explore the psychic, moral, ethical and logical significances in the spectatorship of Bollywood and Tamil film in the Sri Lanka. Bollywood and Tamil film has been taking a very popular cultural performance in Sri Lanka. The original Indian spectatorship of these film traditions has been diverted by the cultural and political psychology of Sri Lanka. Hence, this local orientation of the Indian cinema remains a quite metamorphosis and deconstruction in its appreciation and screening in terms of the social, cultural and political features that deeply-rooted in Sri Lankan history, culture and geographical limitations. For this study, several film texts, which include typical Bollywood and Tamil film characteristic features were used and observed on how they have been absorbed in the Sri Lankan cultural society. And on the other hand, some audience surveys specific to different film appreciation contexts were conducted. They included urban slums, semi-rural Muslim societies, north and east areas of Tamil villages, Colombo urban society, Tamil state areas and Kandyan Sinhala rural villages. In the textual analysis of the film content, implicit psychological narrations and their social and aesthetic interpretations were revealed in the analytical explanations. Using the audience surveys, many different opinions that can be traditionally filtered in the screening and appreciation of these film traditions specific to their living cultural settings were also identified. In conclusion, perception in Sinhala film has been considerably designed by the experience of Bollywood and Tamil film spectatorship is deducted by this study. Hence, not only this social trend affected to the appreciation of film in local general audience but also in all the facets of film production (script writing, shooting, acting, dialoguing, music and choreography and screening) has also significantly being influenced by the Bollywood and Tamil film. As a result of this evolution of local film culture, most recent trend in Sinhala film noir is also being followed by the early subjective consequences of Bollywood and Tamil film culture in Sri Lanka.

Keywords: technical terms, psychological and philosophical reading, Bollywood and Tamil Film, film culture, spectatorship
\end{abstract}

\section{Introduction}

Perception of a live visual medium can be interpreted differently in terms of variety of subjectivities. But, Psychology and Philosophy have contributed many tools and techniques in the objective analysis of a particular text (Rodowick, 2010; Persson, 2003; Buckland, 2004; Metz, 1974). In this context, Film Spectatorship is the fact that takes much concern as Sri Lankan audience used to appreciate and enjoy Indian Hindi and Tamil film with their cultural and regional milieu.

Manoj Jinadasa, MSSc, Senior Lecturer, Department of Mass Communication, Faculty of Social Sciences, University of Kelaniya. 
Bollywood is one of the major popular cinema industry as well as narration depicting agendas of general subjectivism of Indian politics and cultural economy. But, the appreciation and taste of the Bollywood film has taking a global attention. One of the significant aspect for such overwhelming interest is the understanding of the general emotions and morals of the secular behaviors of the human being.

Therefore, when it comes to the local audiences of Sri Lanka, association of Bollywood and Tamil films in their appreciation, it takes some interesting traits and characteristics in the rural mass, urban and semi-urban and remote rural places.

Basically, participatory observation and textual analysis as well as field survey were used to gather and analysis the real social data associated with this phenomena.

\section{Bollywood Film}

India continues to be the largest film-producing country in the world with an annual output of over 700 films. A few years ago the figure was as high as 900 . And nearly 90 percent of these films belong to what critics term the popular cinema as opposed to the artistic cinema as exemplified in the works of such auteurs as Satyajit Ray, MrinalSen and Adoor Gopalkrishnan. Popular cinema is still a dominant force in India providing a useful site for the negotiation of cultural meaning and values and inviting the vast mass of movie-goers to participate in the ongoing conversation of cultural modernities(Gunarathna \& Dissanayaka, 2003, p. 202). The popular cinema of India can be understood most productively within the discursive boundaries of cultural modernity.

Ashis Nandy observes that popular cinema provides the vast mass of movie-goers with the cultural categories with which to make sense of their lives. Popular cinema in India has to be understood in relation to the dynamics of modernization as they impinge on the cultural consciousness of Indian people (Gunarathna \& Dissanayaka, 2003, p. 204).

From its inception Indian cinema drew upon the epics Ramayana and Mahabaratha, which were an animating force of classical poetry, drama, artand sculpture. This influence can be explored in terms of thematics, narrativity, ideology and communication (Gunarathna \&and Dissanayaka, 2003, p. 205). Although, as I shall indicate later, Indian cinema was hugely influenced by Hollywood, the art of narration with its endless circularities, digressions and detours, and plots within plots remained characteristically Indian. In their deployment of humor, music, dance, the structure of the narratives, the informing melodramatic imagination, the folk dramas of India have clearly had a deep impact on the makers of popular commercial cinema (Gunarathna \& Dissanayaka, 2003, p. 208).

However, Hindi films, though comprising approximately 20 percent of total production, are the ones that circulate nationally and internationally, dominate the discourse about Indian cinema, and are regarded as the standard or archetype to follow or oppose. Outside India, the category "popular Indian cinema" tends to denote Hindi films produced in Bombay. The distinctive features of popular Hindi cinema-song and dance, melodrama, lavish production values, emphasis upon stars and spectacle - are common to films made in the southern Indian industries as well. Cinema in India encompasses a great deal more diversity and has a longer history than the Bombay film industry. Even as a British colony, India was the third largest producer of films in the world (Ganthi, 2004, p. 3).

The influence of Hollywood on the makers of popular cinema in India is both deep and pervasive. Indian filmmakers were greatly impressed by Hollywood films and actors and actresses, and sought to adapt the codes 
and conventions of Hollywood cinema to suit local tastes, sensibilities and conventions. Indian film directors found the technical resources that their Hollywood counterparts had at their disposal most attractive and sought to imitate them and create an Indian world of magic and make believe (Gunarathna \& Dissanayaka, 2003, p. 208).

Makers of popular films in India also sought to adopt pathways that differed significantly from some of the conventions and preferred modalities of presentation valorized by Hollywood filmmakers. One of the fundamental tenets of Hollywood filmmaking, for example, is the need to cover up the artifice, the constructedness of firm articulations of narrative. All aspects of film production were perceived as being ancillary to the projection of a realistic and psychologically convincing narrative. As a result, camera angles were largely at eye level; lighting was unobtrusive; framing was aimed at focusing attention on the central action of a given sequence; cuts were made at logical junctures in the unfolding of the narrative: these devices served to foster an illusion of reality and to promote ready identification of audiences with characters appearing on the screen (Gunarathna \& Dissanayaka, 2003, p. 209).

During the past two decades with the growing exposure of Indian audiences to MTV disseminated through national and international channels, Indian filmmakers have seen in it a rich resource for stylistic innovation. The pace of the films, the quick cutting, newer forms of presenting dance sequences, and the camera angles that one now sees in Indian films are a direct result of MTV. Mani Ratnam's films or box-office hits like SatyaorKuchKuchHotaHaibear testimony to this new trend. One reason for the mass appeal of cinema has always been the clever mixture of entertainment and technology (Gunarathna \& Dissanayaka, 2003, p. 210).

The work of Ashis Nandy is extremely important in this regard. He was one of the earliest among contemporary intellectuals in India to recognize the importance of popular cinema as a window that opens onto the wider culture. Nandy is a leading intellectual who has written illuminatingly on such topics as nationalism, modernity, selfhood, science, development, and rationality (Gunarathna \& Dissanayaka, 2003, p. 211).

At the same time we need to examine the various ingredients that go to form Indian popular cinema as a way of assessing their aesthetic significance. Indian popular cinema is a total cinema that is guided by a poetics of excess, in which narrative, spectacle, humor, action, song and dance combine in a loose union to present a cinematic experience whose very constructedness is foregrounded (Gunarathna \& Dissanayaka, 2003, p. 219).

\section{Indian Tamil Film}

The Tamil film industry begins about the same time as Hindi and Bengali cinema in the second decade of the twentieth century. Although it is less known and acknowledged, it is rapidly emerging as a key player within Indian cinema. To date however, relatively little has been written on Tamil cinema. Since its beginning in the silent era, Tamil cinema has grown into a multimillion dollar industry. Located in the Chennai district of Kodambakkam, Tamil Nadu's cinema city, it produces 150-200 feature films annually. It is often referred to as Kollywood, an amalgam of the words Kodambakkam and Hollywood. Tamil cinema has a long history comparable to other Indian language cinemas. Describing the significance of cinema in Tamil society, Baskaran (1996, p. ii) points out that "over the seventy-nine years of its existence, Tamil cinema has grown to become the most domineering influence in the cultural and political life in Tamil Nadu". It would be both impossible and an injustice to outline the entire history of Tamil cinema in this brief introductory chapter. However, the two well known Tamil film historians Theodore Baskaranand Randor Guy have written widely on this topic. In Baskaran's $(1981,1996)$ The Message Bearers: Nationalist Politics and the Entertainment Media in South 
India 1880-1945 and The Eye of the Serpent: An Introduction to Tamil Cinema, and Guy's (1997) Starlight Starbright - Early Tamil Cinema, the only English publications available on the history of Tamil cinema, the authors offer an excellent account of the arrival of cinema to the Madras Presidency at the turn of the twentieth century; the early pioneers of the film industry who were instrumental in setting up production companies and studios; biographies of directors, producers, and actors; and synopses of major films over the years. Though there are other works on the history of Tamil cinema, these are mostly written in Tamil and have not been translated into other languages (Velayutham, 2008, p. 2). Between the 1970s and the 1990s, Tamil cinema was reinvigorated by the arrival of new and young talents as the stars of earlier decades faded away or entered retirement. These three decades saw the entry of the second generation of actors like Kamal Hassan, Rajini Kant, Vijaykanth, Saritha, Sri Devi and so forth in lead roles and major directors such as K. Balachander, Bharatiraja, BaluMahendra, K. Bhagyaraj, T. Rajender and Mani Ratnam (Thoraval, 2000, pp. 318-343). A popular genre that emerged during this period is what Sundar Kaali (2000, p. 170) terms Neo-nativity films that were "characterised by an ideological investment centred on the rurality of its plot-events and roles". Thus, the rustic hero, the village and its social milieu became the preferred site for numerous films produced in this period. Since the 1990s, with the liberalisation of the Indian economy and the rise of an Indian middle class, Tamil cinema has shifted its orientation towards tapping into the sensibilities and taste cultures of this new film audience. The representation of modernity, progress, affluence and global consumerism is its major preoccupation (see Krishnan in this volume). For instance, the urban space and "the city" now serve as the primary backdrop for most films. Films are centred mainly on themes such as romance (teenagers, college youths, and young adults); institutional and bureaucratic inadequacies (hospitals, the police and politicians being the primary target); and the underworld (gangster flicks). In a sense, films are a lot more sensual, intense and explosive in their visual form and this is coupled with a high turnover of new and young actors within the film industry. In 2006, the Tamil film industry celebrated its 75th anniversary and it continues to flourish as a reputable site of cinematic production in India (Velayutham, 2008, p. 2).

When Vasudewan (2010) write on the contemporary trend in Tamil Cinema applied in Sri Lanka reference to Voice, Space, Form: The Symbolic and Territorial Itinerary of Mani Rathnam's Roja (1992) he has made the following criticism:

The linguistic tension between Tamilnadu and the Hindi-speaking northern states has varied in intensity. At the turn of the 1990s, the importance of a distinct Tamil identity was complicated by the emergence of an extremist and separatist movement from with-in the Tamil minority of neighbouring Sri Lanka. The ruling Party of Tamilnadu at that time, the DMK, was supportive of the movement and averse to undertaking any action against Sri Lankan Tamil separatists working out of Tamilnadu; and the Indian government, led by Rajiv Gandhi, conciliated this sentiment. However, it was subsequently involved in a pact with the Sri Lankan government by which an Indian Peace Keeping Force was deployed in an unsuccessful bid to mob the violence. This alienated the Sri Lankan Tamil extremists from be Indian state and led to an extremist group assassinating Rajiv Gandhi in 1990. Subsequent Tamil regimes have distanced themselves from Tamil extremism in Sri Lanka.

It is widely acknowledged that "Indian" cinema is not a homogeneous or singular entity and any attempt to approach this cinema from a "national" perspective is problematic (Rajadhyaksha \& Willemen, 1994; see also Devadas \& Velayutham in this volume). Indian cinema as a text and form is multifarious but far too often adheres to a predictable narrative and fairly standard genre conventions. In their book Indian Popular Cinema, 
Gokulsing and Dissanayake (1998) point out that the "Indian-ness" of Indian cinema can be best understood by closely examining the genres and themes that are pervasive and unique to this industry (Pendakur, 2003).

There are several significant genres in Indian popular cinema and they include mythologicals, devotional, historical, romance, stunt (action), social, family dramas and a combination of these. Indian films are mostly melodramatic, have circular narratives, are formulaic, accompanied by music, song, and dance sequences, fight scenes, exaggerated humour and are three hours long (Gokulsing \& Dissanayake, 1998, pp. 23-33, 91-102). These readily identifiable characteristics of Indian cinema-almost always from the vantage point of Hindi films -indicate that there are certainly common elements that cut across all the Indian language cinemas (Velayutham, 2008, p. 5).

Tamil cinema echoes a distinctly Tamil identity while Hindi cinema (Bollywood) is often regarded as emphasising a pan-Indian identity. The tendencies of separatism and linguistic nationalism asserted by the Tamils in South India are also a salient feature of the Tamil film industry (Velayutham, 2008, p. 7).

Indeed, Tamil cinema, like the other language cinemas of India, always tells a simple story with fanfare, melodrama and predictability. It is deeply moralising, self-righteous, and parochial and upholds the social order; it also seeks to entertain as well as maintain the dominant values of a Hindu Tamil society. But it often always "only" speaks to a Tamil audience. Tamil cinema for a Tamil audience speaks volumes about being Tamil. Where Bollywood nominally transcends such particularistic identities, depicting mostly generic characters, Tamil cinema employs Tamil-Indian identities both as a matter of fact and strategically (Velayutham, 2008, p. 8).

Tamil cinema pervades every aspect of Tamil society and everyday life. As a form of popular culture, it provides not only entertainment to the masses but also an array of existential and ontological points of reference, from cultural identity to the production of norms, values and beliefs, and dissemination of dominant values. In this sense, the subjects addressed by Tamil cinema say as much about Tamil society, its people and culture as they do about Tamil films.

Much of Tamil cinema's preoccupation has been in the generation of entrenched ideas of Tamil culture, tradition and ethno-linguistic nationalism. Its primary audience are Tamils. With an estimated population of 64 million Tamils in Tamil Nadu alone, and movies dubbed or made in other Indian languages (frequently into Telugu, Malayalam, Kannada and Hindi), it can be argued that the Tamil film industry is steadfastly committed to the local Indian market. Outside India, the Tamil-speaking population numbers around 8 million. Unlike the trends in Bollywood cinema since the late 1990s, where explicit connections are made to the Indian diaspora (largely Hindi speaking), catering to their sensibilities and cultural consumption, Tamil cinema has yet to discover the economic potential of its global audience. Tamil cinema remains very much a medium that caters exclusively to the Tamil population in India. In particular, Tamil cinema is highly significant in the reproduction of culture, tradition and identity in the context of the diaspora (Velayutham, 2008, p. 173).

Both Santosh Sivan's The Terrorist (1999) and Mani Ratnam's Kannathil Muthamittal (2002) changed the representation of diasporic Tamil subjects. The Terrorist, a multi-award winning art film, was inspired by the death of Rajiv Gandhi in 1992 by a suicide bomber. It is an emotive and psychologically intense story of a pregnant, militant woman on a suicide mission, who has to choose between life and death. Although the film does not name names or places, it is not difficult to surmise that the woman is a Sri Lankan Tamil Tiger soldier. In Kannathil Muthamittal, another movie that uses the Sri Lankan ethnic conflict as its backdrop, a young Sri Lankan Tamil girl, Amudha, is abandoned by her mother and adopted by an Indian Tamil couple. When the news of her adoption is revealed, Amudha is eager to learn more about her biological parents. The rest of the 
movie takes the audience to Sri Lanka, set against the backdrop of high tension and suicide bombs. Here were two movies that highlighted for the first time some of the predicaments and impacts of the Sri Lankan conflict on women and children. Moreover, they deal with a diasporic community that hardly gets a mention in cinema (Velayutham, 2008, p. 175).

The population of the state of Tamil Nadu remains the single largest market for Tamil films. For these audiences, films depicting diasporic Tamils appear to be less attractive. For them, Tamil cinema is about Tamils for Tamils in India. Even the second largest Tamil community outside India residing in Sri Lanka, as we have seen, is rarely represented in Tamil cinema (Velayutham, 2008, p. 178).

Nonetheless, it is worth noting that the Sri Lankan Tamil cinema and more recently emerging Malaysian Tamil cinema have provided some interesting offerings. According to Jeyaraj (1999), Tamil cinema in Sri Lanka has yet to grow beyond its nascent stage. One of the reasons for this, Jeyaraj argues, is that: Sri Lankan Tamils have been a constructive component of Sinhala cinema right from its inception ... The pre-1983 period saw a large number of Tamils become part and parcel of the Sinhala film industry as producers, directors, cinematographers, music directors, sound directors, technicians and musicians. In fact, the owners of some of the major studios and theatres were Tamils. But with the post-1983 developments in the island, the Tamil presence in Sinhala cinema has become virtually non-existent (Velayutham, 2008, p. 180).

The Sinhala film industry largely financed and regulated by the Sri Lankan government has had variable successes. With Sri Lankan Tamils relying exclusively on South Indian Tamil films and the flourishing Sinhala film industry, the production of Tamil films in Sri Lanka was unviable as a business venture. The first Sri Lankan Tamil movie was Samuthayam (1962) an adaptation of C. N. Annadurai's Velaikkari. This however, was shot on $16 \mathrm{~mm}$ film, and was produced and directed by a Sinhalese, Henry Chandrawansa. The first Sri Lankan Tamil film in standard $35 \mathrm{~mm}$ was Thottakkari (1962). A film based on a plantation worker and directed by M. P. S. Krishnakumar. Among some of the noteworthy Sri Lankan Tamil films are Kuthuvilakku, Ponmaniand Vadakkattru. The first two dealt with the practice of dowry and the third with the tensions between migratory and indigenous fishermen and was shot against the backdrop of Neduntheevu Island in the north-west of Sri Lanka.

\section{Sri Lankan Tamil Films}

South Indian producer S. M. Nayagam played an important role in the development of the first Sri Lankan film. In 1945, Nayagam founded a company named Chitrakala Movietone and constructed a studio in Madurai, India for the purpose of making a Sinhala film. After considering several options, he decided to build the film around the historical love story of Saliya and Asokamala and held a contest to find a suitable screenplay; the winner was budding artist Shanthi Kumar. Due to disagreements however this project fell through and Nayagam broke a deal with dramatist B. A. W. Jayamanne to film his popular play Kadawunu Poronduwa.

However, though that there is a growing film trend of historical Buddhist religious legends and stories in local film production. Hindi Bollywood and Kollywood cinema has been a popular aspect of Sri Lankan audience since the beginning of Indian film traditions. But, in the real audience the way how cinema has been associated has made some interesting differences in almost every parts of the localities.

According to D.B.S Jayaraj (1999) in his paper Sri Lankan Tamil Cinema and the Search for a Distinct Identity stress about an identical Sri Lankan Tamil film genre developed in the post-Independent period as a result of co-existence of Sinhala, Tamil and Muslim ethnicities. As he says: 


\begin{abstract}
One of the positive aspects of the Sri Lankan Tamil film scene has been its ethnic diversity. The cruel ethnic divide was not reflected here. Sinhalese, Sri Lankan Tamils, Tamils of Indian origin, Muslims - they have all been involved in its development. Almost every film has reflected the ethnic diversity of the country-in the form of the cast, technicians and musicians. In the context of cinema, Sri Lankan Tamils comprise indigenous Tamils, Tamils of recent Indian origin and Tamil-speaking Muslims.
\end{abstract}

In that respect, the first Sri Lankan Tamil film was Samuthayam (Society), an adaptation of C.N. Annadurai's Velaikkari. This film, however, was in $16 \mathrm{~mm}$ and in technicolor. While the producer of the first Sinhala film was a Tamil, the producer of the first Sri Lankan Tamil film was a Sinhalese, Henry Chandrawansa. He was its director too. Samuthayam was initially planned as a $35-\mathrm{mm}$ film but later the producer reverted to $16 \mathrm{~mm}$ because of financial difficulties.

Tamil films have not been a vehicle of social and political change in Sri Lanka unlike in Tamil Nadu, where all Chief Ministers from C.N. Annadurai, who came to power in 1967, have been involved in cinema at some time or the other. It is noted that Indian Tamil cinema has had a limited Sri Lankan Tamil connection.

However, there has been a long line of Sri Lankan Tamils involved in Indian cinema in various capacities. Two prominent persons among them, who are active at present, are award-winning director-cum-cinematographer Balu Mahendra and producer-director V.C. Kuganathan.

Thirdly, several well-known personalities of Indian Tamil cinema have had some kind of connection with Sri Lanka: M.G. Ramachandran was born at Madulkelle in Kandy; comedian Chandra Babu spent his early years in Colombo as a student of St. Joseph's College, Maradana; actress Sujatha, whose father taught in Sri Lanka, spent her childhood in Galle; Radhika, daughter of M.R. Radha, also grew up in Wennappuwa from where her mother hails.

Sri Lankan Tamils have been a constructive component of Sinhala cinema right from its inception. The first Sinhala film, Kadawuna Poronduva, was produced by a Tamil, S.M. Nayagam. The pre-1983 period saw a large number of Tamils become part and parcel of the Sinhala film industry as producers, directors, cinematographers, music directors, sound directors, technicians and musicians. In fact, the owners of some of the major studios and theatres were Tamils. But with the post-1983 developments in the island, the Tamil presence in Sinhala cinema has become virtually non-existent.

The first Sri Lankan film in Tamil - as opposed to a Sri Lankan Tamil film —was named Kusumalatha, which was screened on December 29, 1951. It was not a film made originally in Tamil; it was a Sinhala film, Sangavunu Pilithura starring Eddie Jayamanne and Rukmani Devi, dubbed into Tamil. The voice-overs were supplied by Indian Tamil artists. So, this movie cannot be considered to be an authentic Sri Lankan Tamil film.

Three Tamil movies, however, stand out as having reflected Sri Lankan Tamil life in a realistic manner. They are Kuthuvilakku, Ponmani and Vadakkattru (North Wind).

However, as Jayaraj pointed out collapse of Sri Lankan Tamil Film was to mainly for three reasons:

(1) Open Economy paving the way for joint Indo-Sri Lankan productions. When prominent Indian stars came to Sri Lanka and began shooting in familiar spots, the novelty of offering to filmgoers Sri Lankan locations on screen was appropriated by these films. So, indigenous films lost a primary attraction.

(2) The second was the arrival of television and the video cassette. Indian Tamil movies could be now viewed sitting in one's drawing room. The state, on the other hand, did not encourage the local industry by offering incentives. The adverse impact felt by Tamil films from Tamil Nadu and Sinhala films as a result of television and the video cassette was felt even more acutely by Sri Lankan Tamil cinema. 
(3) The third and most important factor that affected Sri Lankan Tamil cinema was the ethnic violence of 1983 and the continuing escalation of the conflict. Sri Lankan Tamil society itself was torn asunder and uprooted by the ongoing conflict. This led to a moratorium on all meaningful cultural activity. Internal displacement and migration to other places became the reality of life for Sri Lankan Tamils.

Nearly more than hundred productions of Sri Lankan Tamil cinema were made possible in the post-independent period. Spectatorship for the Sri Lankan Sinhala and Tamil films was serially decreased by the widely expansion of Indian Tamil films and Indian Hindi films.

\section{Sri Lankan Film Spectatorship of Bollywood and Indian Tamil Films}

Basically, almost all the parts of Sri Lanka, including rural, urban and semi-urban sectors have been engulfed with the Indian popular cinema, But Tamil cinema has been limited only to a small number of audience in comparison with the Hindi film audience. From the very beginning of the Indian popularcinema, Sri Lankan film spectators have been attracted by the Indian musical and commercial film industries. After the open economy, existing Sinhala film culture was undervalued by the foreign film industries. In this Indian Hindi Film has been taking as a significant demand. Indian Hindi Film was instrumental in the origin and growing stage of Sinhala Cinema along with its narration and art. Musical narration and the immense association of Indian oriental music and Indian dancing were two major characteristics of the Indian cinema, which primarily affected towards the local film industries of the Sinhala Film ordnance. This is well visible in the Kadaunuporonduwa, which is the landmark of the Sinhala film history in 1945. Many Sinhala Film scripts and productions were influenced and based on the Indian popular musical and theatrical film contents and narrations.

On the Contrary, when it comes to the Sri Lankan local Tamil film tradition, it was not in such an exposure from Indian Tamil film in the early stages of the Sri Lankan Tamil film origin and Development. But the time past, the character of the Sri Lankan Tamil film genre was being limited by many social and political changes that deeply rooted in the local economic and political transformation associated with the western dominant influence towards local industries. As a result of this, Sri Lankan Tamil film culture was replaced by the most and widely circulated Indian Tamil Film industries.

In other words, Sinhala film culture was replaced by the widely popular and romantic Bollywood film. And national Tamil film culture was also deserted by the Indian Tamil film. There are number of reasons for this changing transformation in the local film spectatorship that fundamentally absorbed in to the film culture of Sri Lanka in the recent decades mostly after the open economic change in 1978.

By the mid-80s, Indian Tamil film was produced in video film cassette and it circulated among every social strata. In this, Indian Tamil film was widely appreciated up to the middle class of a variety of social strata including rural mountains, urban, semi urban and some of the prestigious classes. This Indian Tamil films were exceptionally popular by the extreme heroic and fighting stories and narrations.

Meanwhile, Indian Hindi film was also widely expanded among local middle class from 1960. However, with the modern development of technological and artistic application of the American Hollywood film industries, which was the base for the Bollywood, Hindi film copies were highly spread among each and every social strata with out any limitation by the end of the 90s. In the early stages of the high expansion of Indian Hindi film, it was made in Compact Dick (CD). And by the mid-2000, they were highly produced by the modern new media technologies. DVD and Online Internet based film copies are two major social and audience centered media that both Indian Tamil and Hindi film distributed among its fan. 
On the Other hand, despite of the fact that Bollywood film has been much popular among rural and lower middle class of the urban sectors via the media of CD, DVD, and TV contents, Some of the major film halls in Colombo such as Bambalapitiya Majesties City Film hall, Liberty hall of the Kollupitiya and Savoy of Wellawatta are reserved for the Bollywood films for spectators of the middle class of Colombo. These Colombo audience are used to go for the first-hand Bollywood films in these respectable halls. And also these film halls screen the most updated film simultaneously with the film screening of the Indian Film halls.

In addition, Bollywood films are telecasted in many Sri Lankan TV channels, there are another specific television channels for Indian Hindi and Tamil films. For example VarnamTV (Earlier VettriTV) is fully devoted to telecast Indian Tamil films. Many Television spectators have been used to watch TV for Indian popular Hindi and Tamil films.

Recent Sinhala commercial film productions such as Sikuruhate, King Hanthar, Ko Mark No mark are highly influenced by the genre of Indian Commercial film. But these Sinhala film productions are not rich like the Indian Commercial films as they are limited by the local technology and the use of film techniques with the modern film art.

However, though Sinhala film has not been developed to a slandered level of Bollywood, Sinhala film has been exposed by the Indian popular film industry from the inception of local film tradition up to modern commercial and certain classical film productions. One of the recently interesting landmark in the Sinhala film is the use of indian actors and actresses for the local films. For example, one Indian bolllywood actress was invited to act for the character of Paba of the film of KusaPaba. And another film Siddhartha was much popular as the main character, who is Siddhartha was played by a new Indian Nepalease young handsome male and for the character of Dewadaththa, who is the chief opponent of the story of the Siddartha was played by a popular TV reality actor in India.

And also another significant aspect of the association of Bollywood in the Sri Lankan Film culture is the use of local location for Indian Bollywood excellent productions. For example some of the acts of Water and Mid Night Children of Deepa Mehtha were shoot in the Sri Lankan locations with some of the local actors and supporters.

Some Bollywood films were produced based on the Sri Lankan North Eastern LTTE problem. For example some of the local incidents and stories were narrated in the recently made films of Madras Café, and Chennai Express. Both these two films were stunned by the involvement for their main characters by two Indian Stars; John Ebraham in Madras Café and Shah Rukh Kahn in Chennai Express.

In comparison, more or less Indian popular Hindi and Tamil films were basically instrumental in the inception and develop of the Sinhala film industry and film art than the European and Hollywood film sectors and industries. Film producers, Actors have been taking their experiences and training in India and Film studios were also in India in the origin of Sinhala Film. Indian popular actors and actress were the role model for Sri Lankan film industries form the origin up to modern time's local film productions except some 21 st century experimental film production made by recent local film producers. For example, Ashoka Hadagama, Vimukthi Jayasundara, Prasanna Vitanage, Prasanna Jayakodi are some of the modern Sri Lankan experimental film directors exceeding from traditional Indian film traditions.

Albeit more audiences are interested in both Hindi and Tamil films, Teens and youth people are highly engaged in the Indian popular Hindi films, But in the Tamil films it shows a relative minimal audience attraction. 
Sri Lankan young generation have been long attracted by the Indian popular films. This can be discussed in a broad perspective:

First, as Indian Hindi films focuses on the worldliness and secularism in a very sensational and romantic way, film story and narration is produced by regional local concepts of heroism and conflict of a binary opposition in proponent and opponent. This is one of the significant aspect that Indian Hindi film and Tamil film receive much spectatorship among Sri Lankan audience.

Second, use of Indian oriental music and variety of dancing forms in the formation and establishment of Indian film genre is also significant for the much popular audience towards the Bollywood and Tamil films.

Third, the regional culture and society is much concentrated in the script and direction of the film text reasons for the long lasted audience towards Indian popular film and particularly for the Indian Tamil films.

Forth, historical and cultural proximity is the fact that Sri Lankan spectator takes a broad affection with Indian cinema. Communication systems and their styles, cooperation in social dialogues, ethnicity and social harmony are some of the salient aspects of this bondage.

Fifth, Creativity and the fashionable use of performance in choreography and musical soundness that makes a nice blending of classical and folk traditions has been one of the serious effect on growing attraction on the Indian Bollywood film and Tamil film.

And the final point is the timely updating on the technological and scientific development of the material use in the film production and complete direction. Young generation and all the other strata of the society see a difference and social change in the use of newly developed narration and editing systems in the Indian Bollywood films and Tamil films.

\section{Conclusions}

This study concludes that Indian Bollywood and Tamil film has made a strong audience and spectatorship in Sri Lanka for fundamentally its cultural and historical relations with the Sri Lankan Mass consciousness and psychology. Narration and cinematic formation of the Bollywood film has affected towards the immense audience and spectatorship. Despite of the fact that differences between Tamil and Hindi film genres, they both contributed to develop the film culture and aesthetic appreciation in the local cinematic societies.

Though Sri Lankan Sinhala and Tamil film tradition remains a specific and local cultural disposition, from the origin and expansion of the Sri Lankan film production, creation and its technical aspect of creative development and also the public spectatorship have been largely affected by the Indian Commercial film genre.

The fact that the Indian Tamil Film noir, which is full of the devastation cultural nature of the south Indian politics and crime has been a significant psychological reason to get a much attention from the teen and youth generation towards Tamil films. But the Sri Lankan Tamil film, which had hold a substantial difference from Indian Tamil was much concentrated and focused on the local Sri Lankan Cultural creations and behavior. Sri Lankan Tamil Film drew the attention on the significance of the harmony of local ethnicities and the breath and wealth of the diversity of a variety of cultures of Sinhala Buddhist, Tamil Hindu and Islam Muslim. However, as a result of the ill effects of Open Economy from 1978, and the high cinemaorder from the foreign film Industries barred the development of a local Sri Lankan Tamil film genre. On the other hand, this economic and social openness made the possibility to circulate and draw much popular towards Indian Bollywood and Indian Tamil film among local audience. 
On the contrary, while Bollywood and Indian Tamil film has made a significant popular and circulation among Sri Lankan teen and youth generations, contemporary experimental film production of the modern times from mid 90s have been severely abandoned by the teen and youth audiences. Hence, modern teen and youth audience are heavily hallucinated and opiated by the romantic relationships and dreamy world that deeply narrated in the Indian commercial and political film.

Although there was a solid relationship and inspiration with Indian Hindi and Tamil film on the Sri Lankan Sinhala and Tamil films in their origin and development, at present in the contemporary experimental Sinhala film production have no further nurturing substantially from Bollywood and Indian Tamil. On the one hand present film productions have taking much nourishment from European film genres, on the other hand there is an emerging trend of the local historical and Buddhist religious film tradition. For example Abha, Mahindagamanaya, SiriDaladaGamanaya, SiriParakum, SriSiddarthaGauthama, AlokoUdapadhi are some of them, which have not taking much exposure from modern Bollywood and Tamil films as the previous times.

In this juncture, Indian Hindi and Tamil film, on the one hand make a sound circulation among its interested spectators covering each and every social strata, and on the other hand these film traditions make a persistent psychological power for eradicating practical social and political challenges that deeply rooted in the south Asian developing societies. This has been more realistic as these film cultures produce a highly mythical and unrealistic fantasy amidst increasing economic and political failures in the target societies of Indian Hindi and Tamil films. This contradictory has made a another third social mind that lead to forget the real world social, economic and political issues of the lives of the poverty embedded, media illiterated spectators. Instead of developing the social literacy through the art and appreciation of cinema in the south Asian region, particularly Indian cinema has made a concrete myth and hallucination among its spectators through the commercial and musical application in the fantasy forms of cinema narration. This situation has been much negatively affected among Sri Lankan spectators as their literacy of cinema and media has been comparatively minimal with the language literacy, So that the Indian Hindi and Tamil film has made a significant popular and attraction in the local spectators in almost all the social strata in the Sri Lanka.

This substantial influence of the Indian cinema has created the modern religious, historical and dreamy Sinhala film series, which is significantly affected to low the standard and quality of the art and appreciation of the local film spectators. However, on one hand after the decade of 90s modern youth experimental film producers create new philosophical reading with the use of local social and cultural issues in their new cinema using European film styles and narrations, on the other hand, some people invest for religious and historical film productions focused on the Indian film audiences for the maximum economic advantages. Hence, this widely popular local religious and historical film directly target on the spectators of Indian Hindi and Tamil film, who have long been practiced the very fantastic and dreamy world that can be enjoyable in the emotional and subjective feelings of the inner mind. In other words, this local Sinhala religious and historical film production replaced the mass mind and mass consciousness of the tamed Sri Lankan audience of the Indian Hindi and Tamil film for long time.

\section{References}

Anthony, R. G. (1997). Religious conflict, popular culture and the troubled spectators of recent Indian film. Contemporary South Asia, 6(2), 177-189. 
Buckland, W. (2004). The cognitive Semiotics of film. Cambridge, UK: Cambridge University Press.

Crane, D. (2014). Cultural globalization and the dominance of the American film industry: Cultural policies, national film industries, and transnational film. International Journal of Cultural Policy, 20(4), 365-382.

Cubitt, S. (2004). Cinema effect. Cambridge: The MIT Press.

DasGupta, C. (1969). Indian cinema today. Film Quarterly, 22(4), 27-35.

Dwyer, R. (2006). Filming the Gods: Religion and Indian cinema. London: Routledge.

Gopinath, G. (2000). Queering Bollywood. Journal of Homosexuality, 39(3-4), 283-297.

Gunarathna, A., \& Dissanayaka, W. (2003). Rethinking third cinema. New York: Routledge.

Hemphill, L. (2012). Tamil cinema: The cultural politics of India's other film industry. South Asia: Journal of South Asian Studies, $35(3), 758-760$.

Jinadasa, M. (2015). Internet through mobile phone and its cognitive and behavioral impact: Changing sexuality. Journalism and Mass Communication, 5(12), 614-628.

Jinadasa, M. (2015). Rate of crime and the involvement of army soldiers in Post Conflict society in Sri Lanka: Gender representation in crime and lack of the psycho-social awareness in the army profession. Review of Journalism and Mass Communication, 3(2), 41-57.

Jinadasa, M. P. K. (2010). The difference of concepts of the societies of pre-media and post-media: Absence of a moral and ethical justice in sexuality in online media society. Proceedings from IPRC International Postgraduate Research Conference. University of Sri Kelaniya, Kelaniya, Sri Lanka.

Jinadasa, W. W. M. P. K. (2015). Community development programmes and folk-media: A communication model for Sri Lankan rural society. Retrieved from http://www.caluniv.ac.in/global-mdia-journal/Winter\%20Issue\%20December\%20\% 202011\%20Articles/AR-4\%20Jinadasa.pdf

Jinadasa, W. W. M. P. K. (2015). Teen culture: A production of modern popular television and new media texts. Proceedings from Peradeniya University International Research Sessions-2015. Faculty of Engineering, University of Peradeniya, Peradeniya, Sri Lanka.

MacDonald, S. (2006). Art in cinema: Documents toward a history of the film society. Philadelphia: Temple University Press.

Metz, C. (1974). Film language: A semiotics of the cinema. Oxford, UK: The Oxford University Press.

Mishra,V. (2009). Spectres of sentimentality: The Bollywood Film. Textual Practice, 23(3), 439-462.

Murty, M. (2012). Film and media scholarship on contemporary India: The assemblage, the narrative, and "Bollywood". India Review, 11(4), 259-268.

Pauwels, H. R. M. (2007). Indian literature and popular cinema: Recasting classics. Oxon: Routledge.

Persson, P. (2003). Understanding cinema: A psychological theory of moving imagery. Cambridge, UK: Cambridge University Press.

Pugsley, P. C., \& Khorana, S. (2011). Asserting nationalism in acosmopolitan world: Globalized Indian cultures in Yash Raj Films. Continuum: Journal of Media \& Cultural Studies, 25(3), 359-373.

Ranganathan, M., \& Velayutham, M. (2012). Imagining Eelam Tamilsin Tamil cinema. Continuum: Journal of Media \& Cultural Studies, 26(6), 871-881.

Ravi, S. (2008). Tamil identity and diasporic desire in a Kollywoood comedy: NalaDamayanti (2003). South Asian Popular Culture, 6(1), 45-56.

Robinson, A. (2010). An overview of contemporary Sri Lankan cinema: Aphotographic essay. South Asian Popular Culture, 8(3), 325-341.

Rodowick, D. N. (2010). After images of Gilles Deleuze's film philosophy. Mineapolis, USA: University of Minnesota Press.

Shandilya, K. (2014). Of enraged shirts, gyrating gangsters, and fartingbullets: Salman Khan and the new Bollywood action film. South Asian Popular Culture, 12(2),111-121.

Shary, T., \& Seibel, A. (2007). Youth culture in global cinema. Austin, USA: University of Texas Press.

Thejaswini, G. (2004). Bollywood: A guide book to popular Hindi Cinema. NewYork, USA: Routledge.

Vasudevan, R. (2011). The Melodramatic public film form and spectatorship in Indian cinema. London: Palgrave Macmillan.

Velayutham, S. (2008). Tamil Cinema: The cultural politics of India's other film industry. New York, USA: Routledge.

Virdi, J. (1962). The cinematic imagination: Indian popular film as social history. New Brunswick, USA: Rutgers University Press.

Zhang, J. (2014). Genre in Asian film and television: New approaches. Journal of Media Practice, 15(1), 66-67. 